\title{
The effects of togu-jumper use on core muscle activity during plank exercise
}

\author{
Hae-Seong Moon ${ }^{1}$, Woen-Sik Chae ${ }^{1 *}$, \& Jae-Hu Jung ${ }^{1}$ \\ ${ }^{1}$ Kyungpook National University
}

[Purpose] This study was to analyze and compare series of muscle activities during plank exercises with use of togu-jumper. [Methods] Ten male subjects (age $26.9 \pm 1.7 \mathrm{yrs}$, height $172.2 \pm 5.7 \mathrm{~cm}$, weight $66.5 \pm 7.5 \mathrm{~kg}$ ) who have no musculoskeletal disorder with one's upper or lower limb were selected as subjects. To analyze and compare series of muscle activity, five of surface EMG electrodes were attached to the upper rectus abdominis (URA), lower rectus abdominis (LRA), external abdominal oblique (EO), erector spinae (ES) and gluteus maximus (GM). Each subject did plank exercise on stable support surfaces (normal surfaces) and unstable support surfaces with the togu-jumper. For each dependent variable, one-way ANOVA with repeated measures were performed with significance level $\mathrm{p}<.05$. Contrasts were performed to execute post tests for results with statistical significance. [Results] The study showed that the average IEMG values of URA and LRA increased in Upper (Togu-jumper used upper limb) compared to normal surfaces. This is perhaps because the effects of URA more than any other muscles for body stability. Furthermore, the peak IEMG values of LRA increased in Upper and Lower (Togu-jumper used lower limb) compared to normal surfaces. In addition, peak IEMG values of EO increased in Upper compared to Normal. This may have resulted due to momentary strong muscle activity in LRA and EO to correct body posture and balance. Therefore, using Togu-jumper on upper limb maximizes the performance of core training in plank exercise. [Conclusions] The study may be further applied to a method for effective training. It is considered that research and analysis has to be further done on modified plank exercise. Additionally, it is necessary to analyze not only global muscle but also local muscle, as a comprehensive research, to suggest ideal method for plank exercise.

Key words: togu-jumper, core muscle, plank exercise

\section{서 론}

경제성장과 과학문명의 발달은 인류의 생활을 보다 편 리하게 만들었지만, 신체활동의 감소와 과잉영양공급 및 동물성 지방의 과다섭취로 만성질환의 주요인자인 비만

논문 투고일 : 2020. 07. 21.

논문 수정일 : 2020. 09. 04.

게재 확정일 : 2020. 10. 12.

* 교신저자 : 채원식(wschae@ knu.ac.kr).

* 이 논문은 2020 학년도 경북대학교 연구년 교수 연구비에 의하여 연구되었음.
을 초래하게 되었다. 특히 운동 부족에서 기인하는 비만, 고혈압, 관상동맥질환 등의 발병이 점차적으로 증가하고 발병연령 또한 낮아지고 있는 추세이다(Choi, 2000).

우리나라도 과거와 비교해 보면 비만도가 높아지는 추 세로 비만과 관련된 질환이 급증한 것으로 조사되었다. 보건복지부 질병관리본부가 발표한 '2015 건강행태 및 만성질환 통계'에 따르면 국내 성인 남성 중 비만인 사람 은 전체의 $39.7 \%$ 로 나타났다. 이는 1998년 25.1\%에서 2008년 35.3\%까지 급증한 후로도 꾸준히 증가한 것이 다. 같은 기간 국내 성인 여성 비만은 $26.2 \%$ 에서 $25.2 \%$ 
로 $1 \%$ 감소한 후 2015년 26\%로 비슷한 수준을 유지했 다. 우리나라 성인 전체로 본다면 19세 이상 비만이 2015년 34.1\%로 1998년 26\%에 비해 8.1\%포인트 늘 어난 것이다.

비만을 예방하거나 치료하는 방법은 매우 다양하지만, 그중 식이요법과 운동요법이 권장되고 있다. 식이요법은 섭취 열량만을 제한하는 것으로 단시간 내 일시적인 체중 감량효과가 크지만, 기초대사량과 상관이 높은 제지방 체 중의 감소를 초래하게 된다. 따라서 식이조절프로그램보 다는 운동요법을 병행한 체중감량프로그램이 제지방 체 중을 유지 및 증가시키고, 체지방을 효과적으로 감소시키 는 것으로 알려져 있다(Schwartz et al., 1991). 특히 운 동을 통한 체지방 감소는 체력을 유지하고 향상시키는 효 과가 있다(McInnis, 2000).

일반적으로 체지방 감소를 위한 운동은 걷기와 달리기 같은 유산소성 운동이 활용되었지만, 최근에는 바쁜 현대 인들이 시간과 장소에 구애받지 않고 간편하게 집에서 할 수 있는 홈 트레이닝이 주목받고 있다. 홈 트레이닝은 집 에서 간단한 운동 환경을 만들어 컴퓨터나 스마트폰을 사 용해 관련 앱(APP)이나 유튜브(YouTube), SNS 등에서 얻어진 정보를 참고해 운동을 하는 방법이다. 이러한 트 레이닝 방법은 날씨에 상관없이 운동을 할 수 있으며, 운 동을 하기 위해 헬스장을 찾을 필요가 없어 시간과 비용 적인 부분에서 큰 이점이 있다. 다양한 홈 트레이닝의 운 동방법 중 신체의 중심부인 코어(core)를 강화하기 위한 운동이 가장 흔히 활용된다.

코어 (core)는 복강과 흥강을 나누는 경계선이 되는 횡 경막 아래에서부터 골반기저근까지의 신체 부위를 말한 다. 코어는 상지와 하지의 움직임에 있어 안정성을 제공 하며, 외부 저항으로부터 몸의 자세를 유지시켜 척추신경 을 보호하는 역할을 한다(Radziminska et al., 2017).

코어운동은 주로 스포츠 현장에서 경기력 향상을 위한 기본운동으로 강조되고 있을 뿐 아니라, 근골격계 환자 중 요통 환자들의 척추 안정화 운동프로그램 등으로 광범 위하게 활용되고 있다(Yang, 2014). 이뿐만 아니라 Lee(2015)는 코어운동이 체중과 체지방, 내장지방의 단 면적을 감소시키며 일상생활에 도움이 된다고 보고하였 다. Cengiz(2013)는 코어운동이 혈중중성지방농도를 감 소시키고 고지질 지방 콜레스테롤 $(\mathrm{HDL}-\mathrm{C})$ 은 증가시키
는 효과가 있다고 보고하였다. 또한 Vehagen et al. (2004)은 불안정한 지면에서의 코어운동은 근신경 전 달체계(neuromuscular delivery system)를 자극하며, 신체 가동성과 균형능력을 향상시켜 운동의 효과를 극대 화할 수 있다고 하였다. 이러한 운동효과는 불안정한 지 면에서 안정된 균형유지를 위해 근신경계의 상호협력 수 축(co-activation)과 협응성이 증진되기 때문으로 알려 졌다(Sung et al., 2005).

일반적으로 알려져 있는 코어 운동으로는 싯 업(sit up) 운동과 레그 레이즈(leg raise) 운동, 플랭크(plank) 운동 등이 있다. 이 중 싯 업 운동은 내·외복사근의 활성 화에는 기여하지 못한다(Vera-Garcia et al., 2000). 또 한, 레그 레이즈 운동은 고관절 굴근의 과도한 작용으로 인해 전방 골반 경사가 일어나 요부의 과신전과 복근의 강한 수축으로 통증이 발생할 수 있다(Larsen, 2005). 이에 반해 플랭크(plank) 운동은 체간 근육의 활성도를 증가시키는 대표적인 코어 안정화 운동으로써, 전신 근육 을 자극해 짧은 운동시간 대비 운동 효과가 크며, 요통 완 화에도 효과적인 운동이라고 알려져 있다(Ekstrom et al., 2007).

지금까지 코어 강화 운동에 대한 다양한 연구들이 이루 어져 왔지만, 대부분 싯 업이나 레그 레이즈 동작에 대한 연구에 국한되었다. 또한, 운동 효과를 극대화시키기 위한 플랭크 동작이나 지지면 변화에 대한 운동 효과 연구는 미 흡한 실정이다. 따라서 본 연구의 목적은 플랭크 운동 시 토구-점퍼 활용이 코어근육의 근활성도에 미치는 영향을 분석하는데 있다. 이를 통해 불안정한 상태 유발에 따른 코어강화 운동효과를 살펴봄으로써 플랭크 운동의 효과적 인 운동방법을 제안하는 근거를 마련하고자 한다.

\section{연구방법}

\section{연구대상자}

본 연구에서는 상·하지 근골격계에 이상이 없는 성인 남성 10 명을 연구대상자로 선정하였다. 연구대상자의 신 체적 특성은 나이 $26.9 \pm 1.7$ 세, 신장 $172.2 \pm 5.7 \mathrm{~cm}$, 체 중 $66.5 \pm 7.5 \mathrm{~kg}$ 이다. 


\section{실험장비}

본 연구의 자료 측정을 위한 실험장비는 〈Figure 1)과 같이 설치하였다.

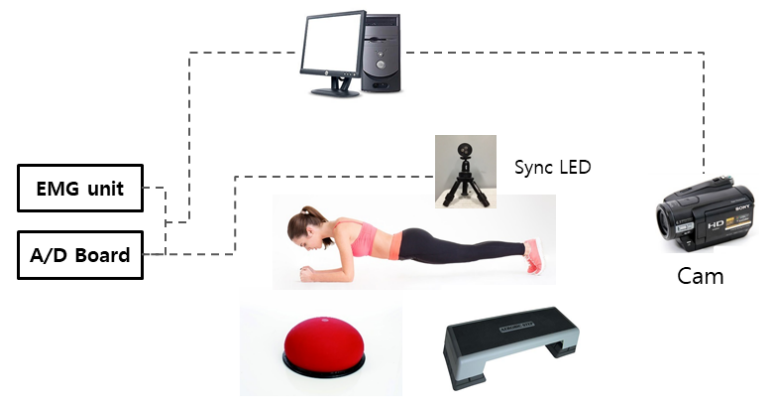

Fig. 1. Experimental setup

\section{근전도 분석}

본 연구에서는 코어근육의 근활성도 측정을 위해 근전 도 측정기기(QEMG-8, Laxtha Inc. Korea, sampling frequency $=1024 \mathrm{~Hz}$, gain $=1,000$, input impedance $>10^{12} \Omega$, CMRR $>100 \mathrm{~dB}$ )를 사용하였으 며, 표면전극은 피험자의 상부 복직근(upper rectus abdominis, URA), 하부 복직근(lower rectus abdominis, LRA), 외복사근(external abdominal oblique, EO), 척추기립근(erector spinae, $\mathrm{ES}$ ), 대둔근 (gluteus maximus, GM)에 부착하였다. 각각의 표면전 극은 근섬유의 수축 방향과 평행되게 부착하였으며, 접지 전극은 전상장골극(Anterior Superior Iliac Spine, ASIS)에 부착하였다(US Department of Health and Human Services, 1992).

\section{토구점퍼}

본 실험에서는 플랭크 동작 시 불안정한 상태 유발을 위해 토구-점퍼 $(52 \times 24(\mathrm{~cm})$, TOGU, GERMANY)를 사 용하였다(Figure 2).

\section{스텝박스}

본 실험에서는 플랭크 운동 시 각 조건간 동일한 자세 유지를 위해 토구-점퍼의 높이에 맞춘 스텝박스 $(98.5 \times 38.5 \times 20(\mathrm{~cm})$, 코어바디, TAIWAN $)$ 를 사용하였 다(Figure 3).
Table 1. Electrode placement

\begin{tabular}{ccc}
\hline \hline Muscle & Electrode placement & MVIC \\
\hline $\begin{array}{c}\text { upper rectus } \\
\text { abdominis } \\
\text { (URA) }\end{array}$ & leg raise \\
\hline $\begin{array}{c}\text { lower rectus } \\
\text { abdominis } \\
\text { (LRA) }\end{array}$ \\
$\begin{array}{c}\text { external abdominal } \\
\text { oblique } \\
\text { (EO) } \\
\text { erector spinae } \\
\text { (ES) }\end{array}$ \\
$\begin{array}{c}\text { gluteus maximus } \\
\text { (GM) }\end{array}$
\end{tabular}

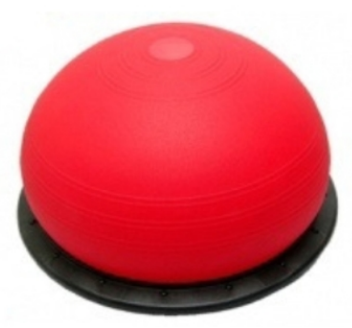

Fig. 2. Togu-jumper

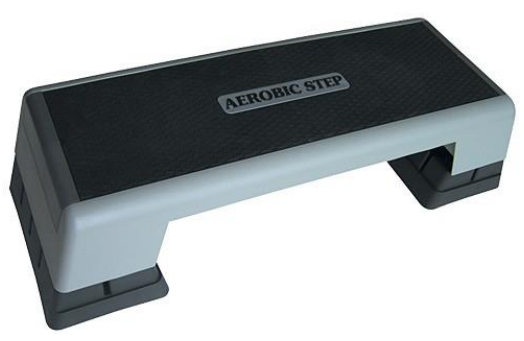

Fig. 3. Stepbox

\section{실험절차}

본 실험에서는 플랭크 동작의 근전도 측정 시 피부저 항을 최소화하기 위해 표면전극 부착 부위의 털을 완전히 제거하고 알코올로 닦은 후 전극을 부착하였다. 또한 근 
전도 자료의 표준화(Normalization) 작업을 위해 〈Table 1)과 같이 근육별 최대 수의적 정적 수축 (Maximal Voluntary Isometric Contraction, MVIC) 을 실제 데이터 수집 전에 실시하였다(Cram, 1998). MVIC 근전도와 실제 근전도 데이터의 샘플링 속도는 $1024 \mathrm{~Hz}$ 로 설정하였다.
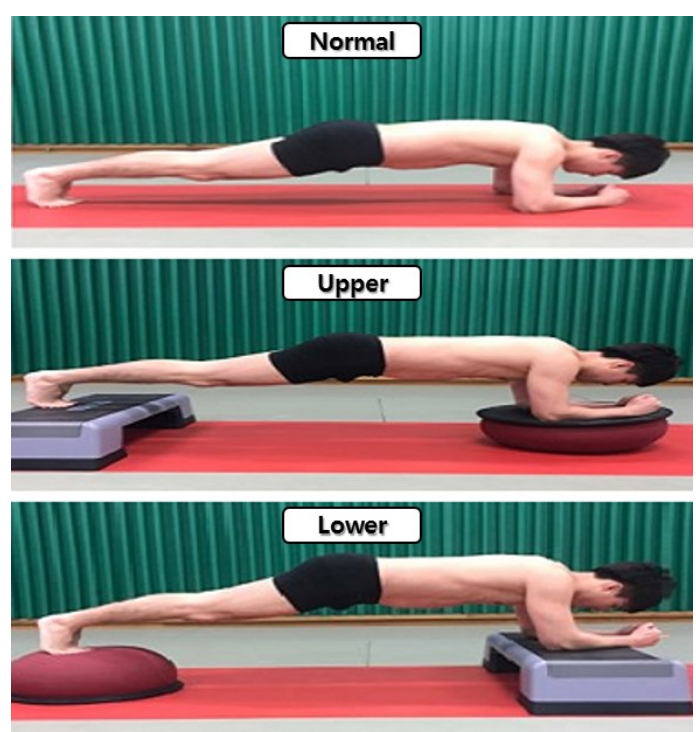

Fig. 4. Plank exercise on different support surfaces

모든 피험자는 실험에 들어가기 전 피로를 유발할 수 있는 강도 높은 신체활동을 금지하였으며, 실험에 앞서 10 분간 가볍게 워밍업을 실시하였다. 본 실험에서는 〈Figure 4〉와 같이 플랭크 운동 시 불안정한 상태를 유발 하기 위한 지지면의 차이에 따라 안정된 지면에서의 일반 플랭크 운동(Normal), 토구-점퍼를 상지에 적용한 플랭 크 운동(Upper), 토구-점퍼를 하지에 적용한 플랭크 운 동(Lower)의 3가지 조건을 적용하였다. 피험자별 3가지 조건의 적용 순서는 무선할당(randomization) 방식을 통해 선정하였으며, 각 조건에 대한 플랭크 동작을 10 초 간 수행하였다. 각각의 실험 조건 적용 간 측정 근육의 피 로 유발을 통제하기 위해 5 분의 휴식시간을 제공하였다.

\section{자료분석}

근전도 분석
플랭크 운동 시 수집된 근전도 자료는 $350 \mathrm{~Hz}$ 의 저역 통과 필터링과 $10 \mathrm{~Hz}$ 의 고역 통과 필터링을 한 후 전파 정류 처리하였다. 이후 플랭크 운동 시 측정된 근전도 자 료를 근육별 MVIC 값으로 표준화하였으며, 10초 동안의 플랭크 동작에 대한 평균 및 최대 적분근전도 값을 산출 하였다. 평균 적분근전도는 실제 플랭크 운동 시 10초 동 안 측정된 근전도 값을 $\mathrm{MVIC}$ 값으로 나눈 후 평균값을 제시하였으며, 최대 적분근전도는 실제 플랭크 운동 시 10 초 동안 측정된 근전도 값을 MVIC 값으로 나눈 후 50 $\mathrm{ms}$ 이동 평균(moving average), Overlap ratio 98\%을 통해 산출한 자료 중 최대값을 제시하였다.

\section{통계처리}

본 연구에서는 플랭크 운동 시 지지면 변화에 따른 근 전도 값의 통계적 유의차를 검증하기 위해 SPSS 23.0을 사용하여 유의성 수준 $p<.05$ 에서 반복측정을 통한 일원 분산분석(one-way ANOVA with repeated measures) 을 실시하였으며, 통계적 유의차가 나타날 시 사후검증을 위해 contrast를 실시하였다.

\section{결 과}

\section{근전도 분석}

\section{상부 복직근 $(\mathrm{URA})$}

플랭크 운동 시 URA의 평균 적분근전도에서는 Upper 조건이 Normal 조건에 비해 통계적으로 유의하게 증가 하였다(Table 2).

Table 2. Average and peak IEMG values of URA (\%MVIC)

\begin{tabular}{cccc}
\hline & Normal & Upper & Lower \\
\hline Average & $13.0 \pm 5.1^{*}$ & $15.3 \pm 4.2^{*}$ & $14.0 \pm 5.3$ \\
\hline Peak & $25.7 \pm 10.9$ & $29.3 \pm 11.4$ & $30.2 \pm 9.8$ \\
\hline \hline
\end{tabular}

Note. *significant difference between Normal and Upper.

\section{하부 복직근(LRA)}

플랭크 운동 시 LRA의 평균 적분근전도에서는 Upper 
조건이 Normal 조건에 비해 통계적으로 유의하게 증가 하였다. 또한 최대 적분근전도에서는 Upper 조건과 Lower 조건이 Normal 조건에 비해 통계적으로 유의하 게 증가하였다(Table 3).

Table 3. Average and peak IEMG values of LRA (\%MVIC)

\begin{tabular}{cccc}
\hline \hline & Normal & Upper & Lower \\
\hline Average & $16.6 \pm 5.1^{*}$ & $22.0 \pm 4.5^{*}$ & $20.0 \pm 5.1$ \\
\hline Peak & $31.1 \pm 7.7^{* \#}$ & $49.7 \pm 10.5^{*}$ & $48.9 \pm 13.2^{\#}$ \\
\hline \hline
\end{tabular}

Note. *significant difference between Normal and Upper. \#significant difference between Normal and Lower.

\section{외복사근(EO)}

플랭크 운동 시 $\mathrm{EO}$ 의 최대 적분근전도에서는 Upper 조건이 Normal 조건에 비해 통계적으로 유의하게 증가 하였다(Table 4).

Table 4. Average and peak IEMG values of EO

(\%MVIC)

\begin{tabular}{cccc}
\hline \hline & Normal & Upper & Lower \\
\hline Average & $16.9 \pm 5.1$ & $19.5 \pm 8.0$ & $18.1 \pm 7.4$ \\
\hline Peak & $25.2 \pm 9.6^{*}$ & $34.4 \pm 12.3^{*}$ & $31.4 \pm 12.8$ \\
\hline \hline
\end{tabular}

Note. *significant difference between Normal and Upper.

\section{척추기립근(ES)}

플랭크 운동 시 $\mathrm{ES}$ 의 평균 및 최대 적분근전도에서는 각 조건간 통계적으로 유의한 차이가 나타나지 않았다 (Table 5).

Table 5. Average and peak IEMG values of ES (\%MVIC)

\begin{tabular}{cccc}
\hline \hline & Normal & Upper & Lower \\
\hline Average & $7.1 \pm 1.2$ & $6.4 \pm 1.2$ & $6.5 \pm 1.2$ \\
\hline Peak & $9.0 \pm 1.6$ & $9.3 \pm 1.3$ & $8.7 \pm 1.5$ \\
\hline \hline
\end{tabular}

\section{대둔근 $(\mathrm{GM})$}

플랭크 운동 시 $\mathrm{GM}$ 의 평균 및 최대 적분근전도에서는 각 조건간 통계적으로 유의한 차이가 나타나지 않았다 (Table 6).
Table 6. Average and peak IEMG values of GM (\%MVIC)

\begin{tabular}{cccc}
\hline \hline & Normal & Upper & Lower \\
\hline Average & $8.0 \pm 3.0$ & $8.2 \pm 2.6$ & $8.3 \pm 2.7$ \\
\hline Peak & $9.2 \pm 2.9$ & $10.0 \pm 2.7$ & $10.4 \pm 3.1$ \\
\hline \hline
\end{tabular}

\section{논 의}

본 연구에서는 플랭크 운동 시 토구-점퍼 적용으로 불 안정한 지면 제공이 코어근육의 적분근전도 값에 미치는 영향을 비교·분석하여 효과적인 플랭크 운동방법을 제시 하고자 하였다. 본 연구에서는 안정된 지면에서의 플랭크 운동, 상지와 하지에 토구-점퍼를 적용한 불안정한 지면 에서의 플랭크 운동 세 가지 조건에서 플랭크 운동을 실 시하여 상부 복직근(URA), 하부 복직근(LRA), 외복사 근 $(\mathrm{EO})$, 척추기립근 $(\mathrm{ES})$, 대둔근 $(\mathrm{GM})$ 의 적분근전도 값을 각각 비교·분석하였다.

불안정한 지면에서 코어운동을 실시했을 시 안정된 지 면보다 코어근육의 활성도가 증가하였다(Marshall \& Murphy, 2005; Sahrmann et al., 2017)는 선행연구의 결과와 같이, 본 연구에서도 토구-점퍼를 적용한 불안정 한 지면에서의 플랭크 운동이 코어근육의 적분근전도 값 을 더 증가시키는 경향이 있는 것으로 나타났다. 하지만 본 연구에서 측정된 모든 근육에서 동일한 결과가 나타나 지는 않았다. 본 연구의 결과를 살펴보면, 토구-점퍼를 상지에 적용할 때 일반 플랭크 동작과 달리, 상부 복직근, 하부 복직근의 평균 적분근전도 값과 하부 복직근, 외복 사근의 최대 적분근전도 값이 통계적으로 유의하게 증가 하였다. 또한, 토구-점퍼를 하지에 적용할 시 하부 복직 근의 최대 적분근전도 값도 통계적으로 유의하게 증가한 것으로 나타났다. 그러나 앞서 언급한 것처럼 이 외의 근 육들에서는 평균 및 최대 적분근전도 값의 유의한 차이가 나타나지 않았다.

불안정한 지면에서 플랭크 운동 시 상부 복직근과 하 부 복직근에서 적분근전도 값이 유의하게 증가한 이유는 신체의 안정성을 유지하는데 있어 다른 근육보다 복직근 이 더 큰 영향을 미치기 때문인 것으로 사료된다. Escamilla et al. (2013)의 연구에서 스위스 볼을 이용한 
플랭크 운동이 복횡근과 내복사근의 근활성을 극대화 시 킨다고 밝혔다. 이와 같이 불안정한 지면에서의 플랭크 운동은 신체의 안정성을 유지하기 위해 본 실험에서 측정 하지 못 한 복횡근, 내복사근 등과 같은 국소근육들의 근 육활동이 더욱 증가할 것으로 사료된다.

토구-점퍼의 적용 위치에 따른 결과를 살펴보면, 상지 에 토구-점퍼를 적용한 플랭크 동작 시 하지에 토구-점퍼 를 적용한 동작보다 상부 복직근, 하부 복직근, 외복사근 에서 적분근전도 값이 다소 높게 나타났으며, 척추기립근 과 대둔근의 적분근전도 값에서는 차이가 나타나지 않았 다. 이러한 결과는 플랭크 운동 시 하지에 불안정성을 증 가시키는 방법이 코어 운동에 가장 효과적이라는 $\mathrm{Do}$ (2014)의 연구 결과와는 상반되는 양상을 보였다. $\mathrm{Do}$ (2014)의 연구에서는 플랭크 동작 시 불안정성을 유 발하기 위한 도구를 상지와 하지에 각각 적용하였는데, 이에 따라 도구가 적용된 신체 부위의 높이가 달라짐으로 인한 플랭크 자세의 변화를 고려하지 못한 차이 때문에 나타난 결과로 판단된다. 본 연구에서는 토구-점퍼 활용 시 동일한 높이의 스텝 박스를 사용하여 일반 플랭크 운 동을 할 때와 같은 자세로 플랭크 운동을 실시했으며, 그 결과 상지에 불안정한 환경을 제공하는 것이 코어근육의 적분근전도 값을 증가시키는데 있어 더 효과적일 것으로 판단하였다. 그 이유는 플랭크 운동 시 인체의 중심이 상 지에 더 가깝게 이동하며, 인체 중심의 위치 변화에 따른 안정성 확보에 더 큰 근육활동이 필요 되기 때문인 것으 로 사료된다.

플랭크 운동 시의 최대 적분근전도 값은 안정된 지면과 비교하여 토구-점퍼를 상·하지에 적용한 불안정한 지면에 서 하부 복직근과 토구-점퍼를 상지에 적용한 외복사근에 서만 통계적으로 유의한 차이가 나타났다. 이러한 결과는 플랭크 동작 중 흐트러지는 자세를 인지하고 바른 자세를 유지하기 위해 순간적으로 하부 복직근과 외복사근에서 강한 근육활동이 발생되기 때문인 것으로 판단된다.

\section{결론 및 제언}

본 연구의 목적은 신체에 이상이 없는 성인 남성을 대 상으로 플랭크 운동 시 불안정한 지면 제공이 코어근육의
적분근전도 값에 미치는 영향을 비교·분석하여 효과적인 플랭크 운동방법을 제시하는데 있다. 본 연구를 통해 다 음과 같은 결과를 얻었다.

첫째, 안정된 지면에서의 플랭크 운동 시 보다 토구-점 퍼를 상지에 적용했을 시 상부 복직근, 하부 복직근의 적 분근전도 값이 통계적으로 유의하게 증가하였다.

둘째, 안정된 지면에서의 플랭크 운동 시 보다 토구-점 퍼를 하지에 적용했을 시 상부 복직근, 하부 복직근, 외복 사근의 적분근전도 값에서 다소 증가하는 경향이 나타났 지만 통계적인 유의차는 없었다.

셋째, 플랭크 운동 시 토구-점퍼의 하지 적용 시 보다 상지 적용 시 상부 복직근, 하부 복직근, 외복사근의 적분 근전도 값에서 증가하는 경향이 나타났다. 하지만 통계적 인 유의차는 나타나지 않았다.

본 연구의 결과, 플랭크 운동 시 토구-점퍼를 상지에 적용할 경우 신체의 안정성 유지를 위해 코어근육의 적분 근전도 값이 증가하게 되며, 이러한 플랭크 운동 방법이 코어근육 강화에 효과적인 것으로 판단된다.

\section{참고문헌}

Cengiz, S. S. (2013). The effects of eight-week core exercises on blood lipids in females. Australian Journal Basic and Applied Sciences, 7(10), 209-214.

Choi, J. (2000). Factors Affecting on Health - Related Physical Fitness of Grown - up Male. The Korean Journal of Growth and Development, 8(1), 53-63.

Cram, J. R. (1998). Introduction to surface electromyography. Aspen publishers.

Do, Y. (2014). A comparison of differnt type of surface during Plank exercise on transversus abdominis and internal obliques thickness using an ultrasound imaging. Ph.D. Dissertation, Inje University.

Ekstrom, R. A., Donatelli, R. A., \& Carp, K. C. (2007). Electromyographic analysis of core trunk, hip, and thigh muscles during 9 rehabilitation exercises. Journal of orthopaedic \& sports physical therapy, 37(12), 754-762.

Escamilla, R. F., Lewis, C., Pecson, A., Imamura, R., \& Andrews, J. R. (2016). Muscle activation among supine, prone, and side position exercises with and without a 
Swiss ball. Sports health, 8(4), 372-379.

Larsen, B. T. (2005). Muscles: Testing and function with posture and pain. Medicine \& Science in Sports \& Exercise, 37(8), 1447.

Lee, H. (2015). The Effects of the Core Exercise on Body Composition, Metabolic Syndrome Risk Factor, and Trunk Muscle Cross Sectional Area for Central Obese Women. Ph.D. Dissertation, Hanyang University.

Marshall, P. W., \& Murphy, B. A. (2005). Core stability exercises on and off a Swiss ball. Archives of physical medicine and rehabilitation, 86(2), 242-249.

McInnis, K. J. (2000). Exercise and obesity. Coronary artery disease, 11(2), 111-116.

Radziminska, A., Weber-Rajek, M., Strączyńska, A., \& Zukow, W. (2017). The stabilizing system of the spine. Journal of Education, Health and Sport, 7(11), 67-76.

Sahrmann, S., Azevedo, D. C., \& Van Dillen, L. (2017). Diagnosis and treatment of movement system impairment syndromes. Brazilian Journal of Physical Therapy, 21(6), 391-399.

Schwartz, R. S., Shuman, W. P., Larson, V., Cain, K. C., Fellingham, G. W., Beard, J. C., Kahn, S. E., Stratton, J. R., Cerqueira, M. D., \& Abrass, I. B. (1991). The effect of intensive endurance exercise training on body fat distribution in young and older men. Metabolism, 40(5), 545-551.

Sung, H., Yang, J., Kim, M., Kang, M., \& Kang, J. (2005). Effects of swiss ball exercise on functional fitness and body sway in male elderly nursing home residents. The Korean Journal of Growth and Development, 13(1), 91-99.

US Department of Health and Human Services. (1992). Selected topics in surface electromyography for use in the occupational setting: Expert perspectives. National Institute for Occupational Safety and Health.

Vera-Garcia, F. J., Grenier, S. G., \& McGill, S. M. (2000). Abdominal muscle response during curl-ups on both stable and labile surfaces. Physical therapy, 80(6), 564-569.

Verhagen, E., Van der Beek, A., Twisk, J., Bouter, L., Bahr, R., \& Van Mechelen, W. (2004). The effect of a proprioceptive balance board training program for the prevention of ankle sprains: a prospective controlled trial. The American journal of sports medicine, 32(6), 1385-1393.

Yang, S. (2014). The effect of core training on isokinetic muscle power of knee joint and lumbar joint in short-distance athlete. Journal of Coaching Development, 16(2), 81-87. 


\title{
플랭크 운동 시 토구-점퍼 활용이 코어근육의 근활성도에 미치는 영향
}

\author{
문해성 ${ }^{1}$, 채원식 $^{2}$, 정재후 ${ }^{1}$ \\ 1경북대학교 학생 \\ 2경북대학교 교수
}

〔목적〕 본 연구의 목적은 플랭크 운동 시 토구-점퍼 활용이 코어근육의 근활성도에 미치는 영향을 분석하는 데 있다. 이를 통해 불안정한 상태 유발에 따른 코어강화 운동효과를 살펴봄으로써 플랭크 운동의 효과적인 운동방법을 제공하고자 한다. 〔방법) 본 연구에서는 상·하지 근골격계에 이상이 없는 성인 남성 10 명을 연구 대상자로 선정하였다. 플랭크 운동 시 코어근육의 근활성도 측정을 위해 피험자의 상부 복직근(upper rectus abdominis, URA), 하부 복직근(lower rectus abdominis, LRA), 외복사근(external abdominal oblique, $\mathrm{EO}$ ), 척추기립근(erector spinae, $\mathrm{ES}$ ), 대둔근(gluteus maximus, GM)에 표면전극을 부착하 였다. 본 실험에서는 플랭크 운동 시 불안정한 상태를 유발하기 위한 지지면의 차이에 따라 안정된 지면에서의 일반 플랭크 운동 (Normal), 토구-점퍼를 상지에 적용한 플랭크 운동(Upper), 토구-점퍼를 하지에 적용한 플랭크 운동(Lower)의 3가지 조건을 적용하였으며, 무선할당(randomization) 방식을 통해 각 조건에 대한 플랭크 동작을 10 초간 수행하였다. 본 연구에서는 플랭크 운동 시 지지면 변화에 따른 근전도 값의 통계적 유의차를 검증하기 위해 SPSS 23.0을 사용하여 유의성 수준 $p<.05$ 에서 반복측정을 통한 일원분산분석 (one-way ANOVA with repeated measures)을 실시하였으며, 통계적 유의차가 나타날 시 사후검증을 위 해 contrast를 실시하였다. 〔결과〕 본 연구의 결과, URA과 LRA의 평균 적분근전도에서는 Upper 조건이 Normal 조건에 비해 통계적으로 유의하게 증가하였다. 또한 LRA의 최대 적분근전도에서는 Upper 조건과 Lower 조건이 Normal 조건에 비해 통계적으로 유의하게 증가하였으며, $\mathrm{EO}$ 의 최대 적분근전도에서는 Upper 조건이 Normal 조건에 비해 통계적으로 유의하게 증가하였다. ‘결론〕 플랭크 운동 시 토구-점퍼를 활용하여 불안정한 조건을 상지에 적용할 경우 상체 전면부의 상·하부 복직근과 외복사근이 주로 동원되는 것 으로 볼 때, 플랭크 동작 중 불안정한 자세가 유발될 경우 복직근과 외복사근이 신체의 안정성을 유지를 위해 중요한 역할을 수행하는 것으로 판단된다.

주요어: 토구-점퍼, 코어근육, 플랭크 운동 